\title{
Correction to: Association of eNOS and ACE gene polymorphisms as a genetic risk factor in gestational diabetes in Iranian women
}

\author{
Mani Mirfeizi ${ }^{1} \cdot$ Mandana Hasanzad $^{2,3} \cdot$ Mahshid Sattari $^{2} \cdot$ Mahdi Afshari $^{4} \cdot$ Davood Abbasi $^{5} \cdot$ Zarin Ajoodani $^{1,6}$. \\ Shahnaz Babayanzad Ahari ${ }^{7}$. Ali Bani Sheykheslam ${ }^{8}$
}

Published online: 25 June 2020

(C) Springer Nature Switzerland AG 2020

\section{Correction to: Journal of Diabetes \& Metabolic Disorders https://doi.org/10.1007/s40200-018-0348-4}

The authors would like to clarify that Shahnaz Babayanzad Ahari was incorrectly removed from the original article and should be included in the authorship. The updated, and correct, author group is shown in this erratum.

Publisher's note Springer Nature remains neutral with regard to jurisdictional claims in published maps and institutional affiliations.

The online version of the original article can be found at https://doi.org/ 10.1007/s40200-018-0348-4

\section{Mani Mirfeizi}

Manimirfeizi@yahoo.com; mani@kiau.ac.ir

1 Department of Midwifery, College of Nursing \& Midwifery, Islamic Azad University, Karaj Branch, Moazen Blvd and Esteglal Blvd Rajaeishahr, Karaj, Alborz 1916893813, Iran

2 Medical Genomics Research Center, Islamic Azad University, Tehran Medical Sciences Branch, Tehran, Iran

3 Personalized Medicine Research Center, Endocrinology and Metabolism Clinical Sciences Institute, Tehran University of Medical Sciences, Tehran, Iran
4 Department of Community Medicine, Zabol University of Medical Sciences, Zabol, Iran

5 Iranian Diabetes Society, Eslamshahr Branch, Eslamshahr, Iran

6 Alborz Hospital, Alborz, Iran

7 Reproductive Health Department, School of Nursing and Midwifery, Tehran University of Medical Science, Tehran, Iran

8 Ghaem Hospital, Alborz, Iran 